\title{
La epidemia de fiebre amarilla en el puerto del Callao durante 1868
}

\section{The yellow fever epidemic in Callao port during 1868}

\author{
Sally Inga Rumiche ${ }^{a}$ y Carlos Carcelén Reluz ${ }^{b}$ \\ Universidad Nacional Mayor de San Marcos \\ a sallyrosaselizabeth.inru@gmail.com \\ bccarcelenr@unmsm.edu.pe \\ https://orcid.org/0000-0001-7645-4955
}

\section{RESUMEN}

En la segunda mitad del siglo XIX fueron redescubiertas las propiedades fertilizantes del guano, para extraer este producto era necesario contar con mano de obra por lo cual se fomentó la migración de trabajadores chinos al Perú. Al coincidir la llegada de ellos con la aparición de la fiebre amarilla se formó el prejuicio de que estos habían introducido la enfermedad al país a través de los miasmas. Al brotar una fuerte epidemia de fiebre amarilla a inicios de 1868, el Estado Peruano, puso en práctica una serie de políticas que buscaban frenar el avance del mal, dichas políticas fueron aplicadas con gran énfasis en el Puerto del Callao, ello debido a que aquí anclaban barcos con tripulación asiática, hecho que lo convertía en un potente foco de infección. Estas políticas consistían por ejemplo en pasar inspección a los buques que arribaban al puerto, y en el caso de ser alguno de estos sospechosos de portar la enfermedad mandarlos a hacer cuarentena a la isla San Lorenzo. Pese a las precauciones tomadas estas no tuvieron el efecto esperado, ya que no contrarrestaban en sí la raíz del problema (la enfermedad se produce por la picadura del mosquito Aedes aegypti) ello debido al desconocimiento científico. Generándose así una serie de prejuicios erróneos hacia los inmigrantes chinos. Para desarrollar el presente trabajo se abordaran tres partes, en la primera se hará una descripción de la coyuntura económica y el proceso de inmigración china, en la segunda parte se describirá la introducción de la fiebre amarilla en el Puerto del Callao y finalmente en la tercera parte se desarrollara las principales medidas que tomó el Estado para frenar la propagación de la fiebre amarilla, asimismo se analizará los prejuicios hacia los pobladores chinos.

\begin{abstract}
In the second half of the nineteenth century, the fertilizing properties of guano were rediscovered, in order to extract this product it was necessary to have labor, which encouraged the migration of Chinese workers to Peru. When their arrival coincided with the appearance of yellow fever, the prejudice was formed that they had introduced the disease to the country through miasmas. When a strong yellow fever epidemic broke out at the beginning of 1868 , the Peruvian State put into practice a series of policies that sought to curb the advance of evil, these policies were applied with great emphasis on the Puerto del Callao, due to the fact that here anchored ships with Asian crew, which made it a powerful source of infection. These policies consisted, for example, of passing inspection to ships arriving at the port, and in the case of any of these suspects of carrying the disease, send them to quarantine to San Lorenzo Island. Despite the precautions taken, they did not have the expected effect, since they did not counteract the root of the problem (the disease is caused by the bite of the Aedes aegypti mosquito) due to scientific ignorance. Thus generating a series of erroneous prejudices towards Chinese immigrants. To develop this work three parts will be addressed, in the first one a description of the economic situation and the process of Chinese immigration will be made, in the second part the introduction of yellow fever in the Port of Callao will be described and finally in the
\end{abstract}

\section{Citar como:}

Inga, S. \& Carcelén, C. (2020). La epidemia de fiebre amarilla en el puerto del Callao durante 1868. Espiral, revista de geografías y ciencias sociales, 1(2), 183 - 195. http://dx.doi.org/10.15381/espiral.v1i2.17141 
third The main measures taken by the State to stop the spread of yellow fever will also be developed, as well as prejudices towards Chinese residents.

PALABRAS CLAVE:

Fiebre amarilla; Callao; Epidemia; Precaución.

KEYWORDS:

Yellow fever; Callao; Epidemic; Caution.

\section{Introducción}

El boom económico del guano iniciado en 1850 hizo evidente la necesidad de contar con mano de obra para la extracción de este producto y otras actividades como la agricultura en las haciendas costeras del Perú, razón por la cual se importaron trabajadores chinos para esa labor. Al coincidir la llegada de ellos al territorio peruano con la aparición de la fiebre amarilla, se generó la creencia de eran los causantes de dicho mal, puesto que serían portadores de los miasmas, descomposiciones orgánicas que causaban la enfermedad al ingresar al cuerpo humano. Una de las epidemias de fiebre amarilla que causó los mayores estragos del siglo XIX fue la de 1868. Debido a ello el Estado Peruano puso en práctica una serie de políticas que buscaban frenar el avance de la epidemia, dichas políticas fueron aplicadas con gran énfasis en el Puerto del Callao, espacio donde anclaban barcos con tripulación asiática, hecho que para el imaginario social lo convertía en un potente foco de infección. El presente trabajo busca responder la siguiente interrogante ¿Cuáles fueron las políticas puestas en práctica por el Estado Peruano en el puerto del Callao durante la epidemia de fiebre amarilla de 1868 ?

Para ello abordaremos el presente trabajo en tres partes, en la primera se hará una descripción de la coyuntura económica de entonces es decir el boom del guano y como esta produjo las condiciones necesarias para la migración de los trabajadores chinos al Perú. En lo que respecta a la segunda parte en esta se mencionara como se llegó a introducirse la fiebre amarilla en el Puerto del Callao y finalmente en la tercera parte se describirá las principales políticas que tomó el Estado para frenar la propagación de la fiebre amarilla, asimismo se analizará las emociones colectivas y prejuicios que existieron en torno a los pobladores chinos en el Callao durante la epidemia de 1868.

\section{El boom del guano y la llegada de los pobladores chinos}

En los albores de 1840 fueron descubiertas las propiedades fertilizantes del guano ${ }^{1}$, razón por la cual sería altamente demandado por países europeos en vías de industrialización, trayendo como consecuencia un incremento en los réditos del Gobierno peruano, lo cual permitió a los mandatarios de turno llevar a cabo "una generosa política fiscal"2. Esto permitió cancelar la deuda externa e interna, abolir el tributo indígena y pagar la manumisión de los esclavos, además de edificar grandes obras públicas tales como las líneas ferroviarias³, el panóptico de Lima, el Hospital

\footnotetext{
1 "El guano es el excremento seco de las aves marinas. La combinación correcta de condiciones naturales, las fuertes profundidades de la corriente del Humboldt, los billones de pequeños peces que esta genera, los millones de aves marinas que siguen sus huellas, dejo con el pasó de los siglos, depósitos asombrosos de excrementos, ricos en nitrógeno y fósforo no lixiviado, que lo convirtieron en el mejor fertilizante natural que la humanidad conoce". Para más información véase: GOOTENBERG, Paul (1998) “El descontento del Guano”. En Imaginar el desarrollo. Las ideas económicas en el Perú poscolonial. Lima: IEP - BCRP, p. 17.

2 MÜCKE, Ulrich (2010). “Burguesía limeña”. En Política y burguesía en el Perú. El partido civil antes de la guerra con Chile. Lima: IFEA - IEP, p. 40.

3 La mayor parte de líneas ferroviarias construidas por el erario público no fueron terminadas o en su defecto no cumplieron las expectativas por falta de mercadería a exportar. En contraste a ello, las pequeñas líneas privadas sí resultaron rentables, ya que partían desde los ingenios azucareros, campos de algodón y las líneas de nitrato hacia los puertos vecinos. Para más información véase: MÜCKE, Ulrich (2010). “Burguesía limeña”. En Política y burguesía en el Perú. El partido civil antes de la guerra con Chile, p. 46.
} 
Dos de Mayo ${ }^{4}$, y asimismo se adquirió embarcaciones como el Rímac (primer barco a vapor), la cañonera Pilcomayo, los monitores Manco Cápac y Atahualpa, entre otros, para la modernización de la Armada peruana.

Para la extracción de este bondadoso producto "no se necesitó contar con una tecnología especial o efectuar una gran inversión de materiales e infraestructura, simplemente había que palearlo en sacos y llevarlo a las naves que lo esperaban" ${ }^{2}$, de allí que se diga que "el guano fue un monopolio sin costo de producción" ${ }^{\text {. }}$ No obstante, a pesar de sólo requerirse mano de obra para su extracción, existieron serios problemas en torno a ello, ya que las "barreras sanitarias como el paludismo que se cebaban en los migrantes serranos al llegar a la costa, sumada a la ausencia de una presión demográfica sobre la tierra que empujara a los campesinos de la sierra a la migración"7 hacían complicado emplearlos como mano de obra, razón por la cual se decidió importar trabajadores chinos para la extracción de este fertilizante.

La migración de pobladores chinos al Perú inició durante el primer gobierno de Ramón Castilla (1845 - 1851), puesto que en durante este periodo se promulgó según la publicación del miércoles 21 de noviembre de 1849 del diario El Peruano una ley por el Congreso de la República en la que se mencionaba "que la agricultura del país se encontraba postrada por la falta de brazos (fuerza de trabajo o como comúnmente se decía, mano de obra), por lo cual era necesario fomentar la migración extranjera y proteger a esos empresario llamados introductores de colones a los que se consideraba que estaban arriesgándose justamente por ser los iniciadores" ${ }^{1}$.Cabe mencionar que la referida ley precisaba las siguientes exigencias para poder introducir a los colonos a nuestro país:

"Los colonos extranjeros podían ser de cualquier sexo, su número no debía bajar de 50 individuos, que podían tener entre diez y cuarenta años [...] por cada colono una vez internado (y cumplidas las condiciones exigidas), el Tesoro Público otorgaría una prima de treinta pesos, para lo cual sería necesario tener a la vista los contratos" ${ }^{\prime \prime}$.

Esta ley además concedía a Domingo Elías y a Juan Rodríguez la exclusividad como primeros introductores por el periodo de cuatro años. El ingreso de los colonos debía hacerse en los departamentos de Lima y La Libertad, al ingresar estos trabajadores a territorio peruano quedaban "extensos de pagar contribuciones y de hacer servicio militar por un lapso de diez años, para lo cual se tendría en cuenta su fecha de ingreso al país"10.

De acuerdo a lo planteado por el historiador Humberto Rodríguez en su artículo El inicio de la trata amarilla al Perú y sus actores (2012) esta ley fue proclamada en un inició con la intención de fomentar la migración en general a nuestro país, sin embargo, al comenzar a introducirse chinos en gran cantidad se le empezó a denominar la "ley china" aunque según su perspectiva debió denominarse "ley chinera" puesto que ella abrió el tráfico amarillo a nuestras costas.

Se puede calcular que entre 1849 y 1874 llegaron al Perú alrededor de cien mil migrantes de origen chino, lo que llegó a significar el flujo migratorio extranjero más

4 RAMÓN JOFFRÉ, Gabriel. (2004) El guión de la cirugía urbana: Lima 1850 - 1940. En ensayos en Ciencias Sociales (3) Recuperado http://sisbib.unmsm.edu.pe/bibvirtualdata/libros/CSociales/ensayos ciencias/v1n1/a02.pdf, p. 14- 16.

5 MÜCKE, Ulrich (2010). “Burguesía limeña”. En Política y burguesía en el Perú. El partido civil antes de la guerra con Chile, p. 38. 6 SHANE, Hunt (2011). "Guano y crecimiento en el Perú del siglo XIX”. En La formación de la economía peruana. Distribución y crecimiento en la historia del Perú y América Latina. Lima: IEP, p. 100.

7 CONTRERAS, Carlos; CUETO, Marcos (2007). “República del guano”. En Historia del Perú contemporáneo, cuarta edición. Lima: IEP - PUCP - Centro de Investigación de la Universidad del Pacífico, p. 140.

8 RODRÍGUEZ PASTOR, Humberto (2012). "El inicio de la trata amarilla al Perú y sus actores". En La inmigración china al Perú. Arqueología. Historia y Sociedad. Lima: Universidad Ricardo Palma - Instituto Confucio - Editorial Universitaria, p. 66.

9 Ídem, pp. 66 - 67.

10 RODRÍGUEZ PASTOR, Humberto (2012). “El inicio de la trata amarilla al Perú y sus actores”. En La inmigración china al Perú. Arqueología. Historia y Sociedad, p. 67. 
elevado del siglo XIX, ellos regularmente arribaban al Puerto del Callao y de allí eran trasladados en carretones o a pie hacia diversas haciendas de la costa, lugar donde reemplazaron la mano de obra de los esclavos africanos ${ }^{11}$.

La mayoría de los chinos partían desde el puerto de Macao, las condiciones higiénicas con las que convivían durante el viaje eran bastante precarias, razón por la cual algunos de ellos adquirían enfermedades en el trayecto "En la mañana de hoy ha fondeado en este puerto la fragata Portuguesa Pedro $1^{\circ}$ procedente de Macao en cuyo puerto embarcó 680 colonos asiáticos de los cuales vienen a su bordo 653 y de estas 14 se hallan con escorbuto"12. En ocasiones más drásticas los culíes terminaban pereciendo ante la enfermedad. En el siguiente cuadro tomado de la memoria del cónsul británico $\mathrm{H}$. Hutchinson, se realiza una de breve descripción de la cantidad de chinos que partieron, fallecieron y llegaron al Callao en la década de 1860.

Tabla $\mathbf{N}^{\circ}$ 1. Inmigración China al Perú en la década de 1860

\begin{tabular}{cccc}
\hline AÑO & LLEGARON & $\begin{array}{c}\text { EMBARCADOS DESDE } \\
\text { MACAO }\end{array}$ & MUERTOS EN EL VIAJE \\
\hline 1860 & 1,413 & 2,007 & 594 \\
1861 & 1,440 & 1,860 & 420 \\
1862 & 1,003 & 1,716 & 713 \\
1863 & 1,628 & 2,301 & 673 \\
1864 & 6,410 & 7,010 & 600 \\
1865 & 4,540 & 4,794 & 254 \\
1866 & 5,929 & 6,543 & 614 \\
1867 & 2,184 & 2,400 & 216 \\
1868 & 4,266 & 4,387 & 121 \\
1869 & 2,291 & 2,366 & 75 \\
1870 & 7,544 & 7,917 & 373 \\
Totales & 38,648 & 43,301 & 4,653 \\
\hline
\end{tabular}

Fuente: Bonilla, Heraclio (1976). "Informe sobre el movimiento comercial del Callao de 1867 a 1870 y parte de 1871 por H. Hutchinson”. En Gran Bretaña y el Perú 1826 - 1919. Informes de los cónsules británicos. Volumen III. Lima: IEP - Fondo del libro del Banco Industrial del Perú, p. 24.

Como se desprende del cuadro anterior, durante los viajes que se realizaron de Macao al Callao, durante la década del 1860, falleció un total del 7\% de trabajadores chinos.

En lo que respecta a su situación laboral esta se encontraba muy cercana al estado de semiesclavitud y frecuentemente sus contratos que oscilaban entre cinco y ocho años eran prolongados en base a mecanismos como el enganche a un periodo mucho mayor.

Con la llegada de los culíes al Perú se solucionó el problema de la mano de obra, no obstante, surgieron otros inconvenientes, puesto que estos nuevos residentes del Perú tenían una serie de hábitos poco comunes para los lugareños, como el de fumar opio, practicar juegos de azar y dejadez en la higiene personal, hechos que no eran bien vistas por la colectividad peruana de aquellos años:

El señor inspector superior de la baja policía, cuyo olfato está ya algo desarrollado, pasó el miércoles último por la esquina del Baratillo -notó un mal olor, husmeó y sin más datos que sus narices se introdujo en la tienda de un asiático, hombre entendido en materia de inmundicias - después de muchos registros se descubrió al pie de la cama del asiático una "olla de modonguito y cuatro de pescado podrido". El inspector mandó

11 ROTTENBACHER, Jan (2013). Emociones colectivas, autoritarismo y prejuicio durante una crisis sanitaria: la sociedad limeña frente a la epidemia de la fiebre amarilla de 1868 (Tesis de posgrado). PUCP, Lima, p. 18.

12 Archivo Histórico de Marina de Guerra del Perú, sección Prefectura del Callao 1868, caja 3, sobre 25, folio 5- 6. Informe del Capitán de Puerto al Prefecto del Callao del 2 de febrero de 1868. 
arrojar el modonguito y el pescado al río e impulsó al dueño una multa de veinticinco soles. Aplaudimos al señor Salguero ${ }^{13}$.

A consecuencia de incidencias como esta, los chinos serán estigmatizados y acusados de originar algunos males que asolaron a la sociedad como la fiebre amarilla.

\section{El arribo de la fiebre amarilla al Puerto del Callao}

La idea de que la fiebre amarilla fue importada por los chinos se basó en el argumento que si bien es cierto la enfermedad había existido en forma endémica en varias ciudades de América desde el siglo XVII, sólo apareció en Lima en "1850 cuando las condiciones ecológicas, sociales se mostraron propias para ello"14, negándose así la posibilidad de que esta enfermedad fuese originaria del Perú.

Una investigación que sustentó esta postura fue del médico francés C. Casset, miembro de la facultad de medicina de París, quien remitió al decano de la escuela de Medicina de San Marcos Miguel de los Ríos, una investigación titulada De la fiebre amarilla en el Perú, en la cual le explicaba que esta enfermedad no podía ser oriunda de nuestro país, ya que él no presenta las características o condiciones climáticas para generarla, por lo cual su presencia sólo podía ser consecuencia de la importación.

"La fiebre amarilla no es oriunda del Perú, ha sido importada en el año 1852. En razón de una situación particular, y de circunstancias climatéricas especiales, el inmenso litoral del Perú, bañado por el Océano Pacífico, no ofrece condiciones favorables al desarrollo espontáneo de esta enfermedad. Sus costas, en mayor parte arenosas, áridas, con mirage, casi estériles, salvo algunos puntos agrícolas, que son como oasis de estos desiertos, gracias á las tempestades de la Sierra, que favorecen en algunos meses con el producto de sus aguas estas á comarcas [...] No existía efectivamente en el Perú esta enfermedad antes del año de 1852, aunque hubiese tiempo atrás, sido endémica en Panamá y periódica en Guayaquil. Por entonces, las comunicaciones eran escasas entre localidades y aun suspendidas, en caso de epidemia. Las cosas mudaron completamente, cuando estas comunicaciones se entablaron de un modo general por medios de los buques de vapor, cuya navegación no ha sido interrumpida en adelante por ninguna consideración. A ellas solas, pues, debe atribuirse la adquisición de este formidable huésped, sin contar tal vez, los que pudieran aparecer con el transcurso del tiempo.

Se deja demostrado que el país no ofrece condiciones propias al desarrollo espontáneo de la fiebre amarilla, siendo justo atribuirlas a las relaciones frecuentes establecidas entre los países, y á admitir como consecuencia, que son precisamente los mismo emigrantes que sirven de vehículos á los gérmenes ó principios tósico de la fiebre amarilla, que ellos van trasmitiendo á otras localidades, mejor tal vez, de lo que haría la atmósfera, pues esta sola enfermedad, no pudo vencer las corrientes atmosféricas, hasta llegar al Callao, ó á cualquier puerto del Perú, vecino del Ecuador; de suerte que, sin estas circunstancias, el Perú estaría, sin duda, todavía libre del flagelo"15

Para poder comprender la propuesta del doctor Casset, hay que tomar en cuenta lo siguiente. Hasta finales del siglo $\mathrm{XIX}^{16}$ el origen de las enfermedades se explicaba

13 Publicación del diario: El Comercio, del 23 de mayo de 1868. Tal como se cita en ROTTENBACHER, Jan (2003). Emociones colectivas, autoritarismo y prejuicio durante una crisis sanitaria: la sociedad limeña frente a la epidemia de la fiebre amarilla de 1868, p. 89.

14 LOSSIO, Jorge (2003). Acequias y gallinazos. Salud ambiental en Lima del siglo XIX. Lima: IEP, p. 67.

15 Archivo histórico de la Facultad de Medicina de la UNMSM: CASSET, C. (1868). De la fiebre Amarilla en el Perú. Lima: Tipografía y encuadernación de A. Alfaro y Ca, folio 3 - 5.

16 Hacia la segunda mitad del siglo XIX el químico francés Louis Pasteur, descubre que las enfermedades eran originadas por microorganismos tales como las bacterias y virus, los cuales se trasmitían mediante la picadura de insectos. Este postulado puso en tela de juicio al paradigma médico que explicaba el origen de las enfermedades mediante los miasmas; su aceptación en la comunidad científica europea empezó a calar en las últimas décadas del siglo XIX. Para el caso del Perú sus antecedentes más remotos se remiten al año de 1889, fecha en la cual el médico Ricardo Flores logró donar un laboratorio de Bacteriología a la Facultad de Medicina y asimismo dictó por un año académico el curso libre de Técnicas Microscópicas y Bacteriología. Al año siguiente la Universidad recibió un subsidio del Estado para el establecimiento de 
en base a dos paradigmas médicos. De acuerdo con el primero, las enfermedades se originaban por las variaciones atmosféricas, teoría que "basándose en la medicina de hipocrática, entendía la enfermedad como producto de las cambiantes condiciones atmosféricas y del influjo natural sobre la salud de las personas"17. En lo que respecta al segundo postulado este planteaba que las enfermedades se originaban por los miasmas que "eran concebidos como imperceptibles seres volátiles producto de la descomposición de la materia orgánica, que buscaban para su desarrollo lugares cálidos, húmedos y sombríos, los cuales ayudados por el calor veraniego se elevaban en la atmósfera y eran transportados por el viento hasta entrar en contacto con un humano"18. Bajo esta lógica las personas se enfermaban por la absorción o intoxicación de un miasma, que tras alojarse en el cuerpo humano generaba la aparición de la fiebre amarilla.

Cabe mencionar que ambas teorías no se contraponen, por el contrario, se complementan, ya que para aquellos médicos que explicaban la enfermedad basándose en la teoría miasmática, las variaciones climáticas provocadas en la atmósfera eran un condicionante que ayudaba a propagar más rápido las enfermedades.

Teniendo en cuenta estas teorías podemos entender por qué para el doctor de la facultad de medicina de París, el origen de la fiebre amarilla no puede ser del Perú, ya que las condiciones climáticas de la costa peruana (lugar donde se desató esta epidemia) son prácticamente estables, salvo en los meses de verano, estación en la cual las lluvias formadas en la serranía bañan las costas, generando así la variación de la humedad que hace alterar la atmósfera, factor que condicionaba la más rápida propagación de la fiebre. Es decir, para el doctor Casset, el cambio atmosférico que sólo ocurría en los meses de verano no era factor suficientemente potente para causar la enfermedad, este era sólo un condicionante más dentro de otros que ayudaba a su rápida difusión.

Casset, al igual que varios médicos peruanos, consideraba que la fiebre amarilla fue importada desde el extranjero hacia el Perú. Admitir que el contagio de la enfermedad era producto de una importación era aceptar la teoría miasmática, razón por la cual los puertos, incluido el del Callao, fueron percibidos como un foco infeccioso, ya que por dichos lugares ingresaban los migrantes extranjeros, quienes eran inevitablemente los agentes portadores. De esta forma se convirtieron los puertos en un lugar "crucial en la difusión de la enfermedad"19.

Otro estudio que sustenta la idea que la enfermedad no puede ser originaria del Perú es la tesis titulada: La fiebre amarilla del Callao en los años de 1888 y 1889, sustentada en 1891 por don Isaías Morales Pacheco para obtener el grado de Bachiller en la Universidad de San Marcos. Si bien es cierto esta tesis es posterior a 1868, periodo delimitado para el presente trabajo, ella nos es de gran utilidad puesto que muestra cómo a pesar de ser la última década del siglo XIX aún seguía vigente la teoría de las miasmas:

"son verdaderamente su cuna como las Antillas, Golfo de Mejíco y costa occidentales del África donde ella reinaba constantemente en los terrenos bajos de los puertos del litoral: en

una cátedra permanente de Bacteriología, la cual le fue asignada al médico peruano David Matto, quién recientemente se había graduado en Inglaterra. La primera fiebre amarilla explicada y tratada bajo este enfoque médico en el Perú será la suscitada entre 1919 - 1920, la campaña preventiva de entonces estuvo a cargo del médico estadounidense Hanson, quien en su objetivo de erradicar la fiebre en Paita propuso incinerar toda la ciudad, para así exterminar a los mosquitos y otros agentes que propagaban dicho mal. Véase: CUETO, Marcos (2000) "Sanidad desde arriba: La fiebre amarilla, la costa norte y la fundación Rockefeller”. En El regreso de las epidemias. Salud y sociedad en el Perú del siglo XX. Lima: IEP, pp. 63, 64 y 70. CUETO, Marcos (1989). “Tradición médica, bacteriología e intervención extranjera en el Perú: 1884 - 1930. En Excelencia científica en la periferia. Lima: Grupo de análisis para el desarrollo - Consejo Nacional de Ciencia y Tecnología, p. 121

17 ZÁRATE, Eduardo (2014). La mayor epidemia del siglo XIX. Lima, 1868 fiebre amarilla. Lima: Eduardo Zárate Cárdenas, p. 37 18 Ídem

19 LOSSIO, Jorge. Acequias y gallinazos. Salud ambiental en Lima del siglo XIX, Lima: IEP, 2003, p. 67. 
los que escinten un gran número de influencia telurica y cósmica, ya sociales é individuales: lo insalubridad de estos puertos por las malas disposiciones higiénicas, la acumulación y fermentación consiguiente de materias orgánicas, favorecidas por la humedad y la alta temperatura de estos climas; sus bruscas variaciones de estío, la evaporación y sequedad de los terrenos despues de las grandes lluvias por un grado escesivo de calórico. Todasesta causas adunadas concurren indudablemente á la formacion de un medio atmosférico miasmático - infeccioso apropiado para el nacimiento del germen amarillo ${ }^{20 "}$

El médico don Isaias Morales Pacheco al igual que el doctor de Casset, señalaba que la enfermedad no era originaría del Perú que la "importación de los objetos en contacto con los individuos atacados, en los focos infecciosos, lo remiten fácilmente, siendo el mar su única vía y los navíos focos móviles de infección con su personal y cargamento" 21 . Otra de las peculiaridades de este estudio es que mencionaba a la "aglomeración de individuos en habitaciones estrechas húmedas y mal ventiladas, la miseria de los desórdenes y escesos de todo género" ${ }^{22}$ como las condiciones propicias para que una casa o un barrio sea atacado por la fiebre amarilla, esta idea será clave para entender los prejuicios y estigmas realizados a los chinos. Por otro lado en lo que respecta a los síntomas de la fiebre amarilla, según esta misma tesis, estos eran los siguientes:

"[...] discrasia de la sangre desórdenes generales profundos en el organismo con tendencia a localizar en los organismos digestivos, á lo que podemos añadir: la acompañada del tinte amarillo en las conjuntivas y en la piel, supresión de la orina, vómitos y cámaras negras, de un pulso lento ${ }^{23 "}$

Desde la aparición de la fiebre amarilla, a mediados de 1852, esta enfermedad se presentó de manera recurrente en el Perú ${ }^{24}$, siendo la epidemia de 1868 la causante de los mayores estragos.

\section{Epidemia de fiebre amarilla de 1868 en el Callao y las políticas de amortiguamiento}

Uno de los primeros casos que hicieron sospechar a los médicos, la posible presencia de la fiebre amarilla surgió en el puerto del Callao. A mediados del mes de febrero de 1868 fue mandado a llamar el médico José Almenavas, para asistir al señor N.N, quien se encontraba alojado en el tercer piso de una de las casas del señor Tadeo Terry ${ }^{25}$ ubicada en la cuadra del Melchor Malo, debido a que presentaba serios dolores de cabeza y vómitos, los cuales de acuerdo con el testimonio del enfermo eran producto del viaje en altamar puesto que tenía pocos días de haber arribado al Callao. No obstante, al no aliviarse de los malestares, decidió llamar al médico, quién a pesar de

20 Archivo histórico de la Facultad de Medicina de la UNMSM: MORALES PACHECO, Isaias. Fiebre Amarilla en el Callao en los años 1888 y 1889. Tesis para obtener el grado de Bachiller en la Facultad de Medicina de la UNMSM, 1891 , folio 3 - 4.

21 Archivo histórico de la Facultad de Medicina de la UNMSM: MORALES PACHECO, Isaias. Fiebre Amarilla en el Callao en los años 1888 y 1889, 1891, folio 5.

22 Archivo histórico de la Facultad de Medicina de UNMSM: MORALES PACHECO, Isaias (1889). Fiebre Amarilla en el Callao en los años 1888 y 1889 , folio 4.

23 Archivo histórico de la Facultad de Medicina de la UNMSM: MORALES PACHECO, Isaias (1889). Fiebre Amarilla en el Callao en los años 1888 y 1889 , folio 3.

24 A lo largo del siglo XIX, se presume que la fiebre amarilla haya aparecido en el Perú hasta en seis oportunidades, encontramos así a la de 1836 - 1837, 1842, 1851 - 1852, 1853 - 1855, 1857 y 1868 - 1869. CASALINO, Carlota (2001). La muerte en Lima en el siglo XIX: una aproximación demográfica, política, social y cultural. Tesis para obtener el grado de Magíster en Historia. Lima: PUCP, p. 319.

25 El empresario peruano Tadeo Terry a mediados del siglo XIX poseía en la caleta de Valparaíso una importante factoría de vapor, con talleres de carpintería y herrería, donde se torneaba, componía y fabricaba cualquier pieza de maquinaria para los barcos a vapor que navegaban por la Costa, asimismo obtuvo la concesión para la construcción y operación del primer dique flotante peruano y también tuvo a su cargo el faro de madera ubicado en la parte más alta del cerro cabezo. Cabe mencionar además que poseía dos cazas en el Callao, la primera estaba ubicada en el Puerto y la otra en la isla San Lorenzo. HUDTWALCKER MORÁN, José. “Las islas del Callao en los albores del siglo XX: apuntes para su historia”. Revista de María. Número 3, año 2008, p. 66 / Diario El Comercio, 20 de febrero de 1868. 
medicarlo, no logró salvarlo ya que falleció a los pocos días. Este hecho hizo sospechar que no se trataba de una simple fiebre ${ }^{26}$.

Debido a la presencia de casos mortales como este y otros ${ }^{27}$, una junta de médicos agrupados bajo la dirección del doctor Domingo Castañeda, emitieron un acta, el 29 de febrero de 1868, dirigida a la Municipalidad de Lima, en ella presentaban una serie de recomendaciones para evitar la propagación de la fiebre amarilla, ya confirmada para eso entonces. Entre las principales medidas a tomar plantearon controlar el puerto del Callao, ya que ahí arribaban los barcos con pasajeros, quienes de acuerdo con la teoría miasmática eran los portadores de la enfermedad. Este control consistía en inspeccionar a las embarcaciones que arribaban al Puerto, exigiéndoles sus respectivas patentes de sanidad, además se sometía la tripulación a cuarentena en el caso de estar enferma o ser sospechosa de portar el mal.

El lugar que proponían los médicos para el aislamiento era la isla San Lorenzo, en el caso de que las personas provinieran del extranjero. Si por el contrario los enfermos se encontraban residiendo dentro Lima, se proponía ubicarlos en una zona sotaventada (en posición opuesta a la que corre el viento). No obstante, como la construcción de lazaretos en dichos lugares demandaría tiempo, se recomendaba utilizar, provisionalmente, las dos casas de madera que servían de cuarteles en la batería del norte ${ }^{28}$.

Estas medidas recomendadas por la Junta Médica fueron asumidas por el Servicio de Sanidad Marítimo conocida también como el servicio de Sanidad del Litoral ${ }^{29}$. Este servicio trabajaba juntamente con médicos asignados por el Gobierno. La citada junta fue establecida el $1^{\circ}$ de setiembre de 1826 , en ella se mencionaba a los capitanes de puerto, así como a dos médicos de la localidad como miembros de la Junta de Sanidad de Litoral.

Su función consistía en pasar inspección a los buques en compañía del médico encargado. Las visitas se practicaban en el día y excepcionalmente de noche. En casos urgentes, como naufragios, llegadas de correos y arribadas forzosas; las inspeccionaría el mismo Capitán del Puerto o un delegado suyo asociado al médico titular del lugar. El buque que durante la visita ocultase algún pasajero o animal enfermo, sería penado con una multa de 100 soles a 500 soles, según la gravedad del caso, ello quedaba a juicio del Servicio de sanidad Marítimo. En caso de que el buque procediera de una zona donde existiera epidemia alguna, la visita se realizaba por medio de un interrogatorio, conforme con el reglamento del puerto ${ }^{30}$.

Una de las primeras acciones que tomó el Servicio de Sanidad Marítimo ante esta coyuntura, fue ordenar el empleo de los "cuarteles del Norte para que sirvieran de lazareto á los epidémicos de la población y la casa del señor Tadeo Terry ubicado en la isla de San Lorenzo para los que vengan de afuera"31

Cabe mencionar que el empleo de la casa del señor Tadeo Terry como lazareto tuvo su origen en 1866, año en el cual el gobierno a través del Prefecto del Callao, coronel de infantería Mariano Herencia Cevallos, comunicó a dicho comerciante que se requería emplear su casa ubicada en la isla San Lorenzo, de manera provisional como cárcel para los jefes y oficiales arrestados en el Callao.

26 Diario: El comercio, 20 de febrero de 1868

27 De acuerdo a la publicación realizada por el diario El Comercio, el sábado 14 de marzo de 1868, entre los días 19 y 29 de febrero de ese año en el puerto del Callao fallecieron 14 personas víctimas de la fiebre amarilla.

28 Archivo Histórico de la Marina de Guerra del Perú, sección Prefectura del Callao 1868, Acta Médica, folio 2

29 CISNEROS, Carlos; GARCÍA, Rómulo (1898) Guía del viajero. Callao, Lima y sus alrededores. Lima: Editorial Imprenta del Estado, p. 29.

30 CISNEROS, Carlos; GARCÍA, Rómulo (1898). Guía del viajero. Callao, Lima y sus alrededores, p. 29.

31 Diario: El Comercio, 21 de febrero de 1868. 
Ante la respuesta afirmativa, la Tesorería de la provincia del Callao ordenó la inversión de cuatrocientos tres soles con veinticinco centavos, para el pago de obras de carpintería y artículos la mejora de dicho inmueble ${ }^{32}$. Concluido el juicio de estos jefes y oficiales en enero de 1867, la casa del señor Terry pasó a manos de la Prefectura del Callao con el Objetivo "de establecer en ella [...] el lazareto donde deben medicinarse los epidemiados de fiebre amarilla que procedían del extranjero" ${ }^{\prime 33}$

El mecanismo empleado para autorizar el desembarco, durante esta coyuntura, se desarrolló de la siguiente manera, todo buque procedente de un país en donde se estaba desarrollado la fiebre amarilla "debía ponerse en facha, á dos tiros de cañón del puerto, para esperar la falúa de sanidad"34. La cual debía colocarse a "barlovento, y á la voz, recibirá, bajo palabra de honor del capitán, las noticias del puerto de donde viene, la tripulación y número de pasajero que sacó y trae y las enfermedades que han padecido durante la navegación" ${ }^{\prime \prime 3}$.

Si el capitán de la embarcación contestaba que todos estaban sanos y sin contagio, subían a bordo los médicos titulares del puerto don Marcelino Aranda y don J. Arnaiz junto con el capitán del puerto o algún representante suyo, quienes se encargaban de realizar la vista de inspección, ella consistía como ya hemos señalado en examinar la patente de sanidad, las cuales eran de dos clases, la primera llevaba la denominación de limpias o de sucias, mientras que la segunda tenía la denominación de sospechosa. Una vez concluida dicha inspección, los médicos escribían un informe en donde indicaban si se debía autorizar el desembarco o someter a la tripulación a cuarentena.

Por otro lado cabe precisar que durante esta epidemia a pesar de encontrarse muchas embarcaciones sin indicios de la enfermedad, estas eran sometidas a una cuarentena de observación que duraba 15 días por el hecho de provenir de una zona donde existía la enfermedad, posterior a este periodo el médico encargado volvía a pasar inspección y elaboraba un informe el cual elevaba a la Junta de Sanidad de Litoral, está tomando en consideración el diagnóstico ordenaba levantar la cuarentena o someter a la tripulación a una mucho más rigurosa, cuya duración se prolongaba al tiempo que creía conveniente la junta ${ }^{36}$.

Durante la cuarentena estaba prohibido todo tipo de comunicación, incluso hasta para entregarle a la tripulación el alimento existía medidas especiales "Habrá un bote destinado para recibir los víveres de tierra, atado á una distancia proporcionada, para que lo puedan tirar de á bordo, luego que hay sido provisto" ${ }^{\prime 37}$. No obstante, a pesar de las precauciones tomadas, las víctimas de fiebre amarilla iban aumentando diariamente. De acuerdo con la memoria del cónsul británico H. Hutchinson el total de víctimas enterradas en el Callao en 1868 a causa de la fiebre amarilla fue el siguiente:

Tabla $\mathbf{N}^{\circ}$ 2. Personas enterradas en el callao a consecuencia de la fiebre amarilla en 1868

\begin{tabular}{ll}
\hline Cementerios & $\mathbf{N}^{\circ}$ de personas \\
\hline Enterrados de fiebre amarilla en el cementerio nativo & 1,354 \\
Enterrados de fiebre amarilla en el cementerio protestante & 157 \\
Total & 2,500 \\
\hline
\end{tabular}

32 Archivo Histórico de Marina, Dirección de Marina. Copiador de notas de diferentes autoridades, Elcorrobarrutia al Prefecto del Callao, 24 - X - 1866, fol. 62.

33 Archivo Histórico de Marina, Dirección de Marina. Copiador de notas a diferentes autoridades, Elcorrobarrutia al Prefecto del Callao, 22 de enero de 1867.

34 FLORES, Toribio (1862). Compilación de las leyes expedidas desde el año 1821, en lo relativo al servicio de las capitanías de los puertos y de las matrículas, ó sea, guía del comerciante y del banquero, en cuanto á las leyes de la Marina mercante. Callao: Imprenta de M. Gómez y J. Aparicio, p. 18, artículo 103.

35 Ídem, artículo 104.

36 Ídem, artículos 107, 108 y 111.

37 Ídem, artículo 117. 
Fuente: Bonilla, Heraclio (1976). "Informe sobre el movimiento comercial del Callao de 1867 a 1870 y parte de 1871 por H. Hutchinson". En Gran Bretaña y el Perú 1826 - 1919. Informes de los cónsules británicos. Volumen III. Lima: IEP - Fondo del Libro del Banco Industrial del Perú, p.21

Es probable que el número de personas fallecidas a consecuencia de la fiebre amarilla haya sido mucho mayor, puesto que algunos cadáveres no eran enterrados en cementerios, simplemente se le tiraba al mar "[...] se ha descubierto que los peces se alimenta de los cadáveres de asiáticos infectados que son arrojados de los buques" 38 o en su defecto se les enterraba en la isla San Lorenzo, una prueba de esta última afirmación nos llega mediante el parte enviado por el capitán de puerto Manuel Palacios al Prefecto del Callao el 24 de marzo de 1868.

Habiendo tenido conocimiento esta Capitania de que el ponton ingles "Nayode" estaba sirviendo de hospital á individuos epidemiados [...] el medico en su visita ha encontrado tres enfermos graves y uno que ya esta muerto, he dado la órden al sor. Petrie, agente de los vapores para que inmediatamente saque el ponton á sotavento de todos los buques y en la direccion del Dique. Asi mismo he dado órden para que se lleve á la Ysla de San Lorenzo al que ha muerto para que se le de sepultura ${ }^{39}$.

Debido a este aumento sucesivo de muertes, las políticas de amortiguamiento se reforzaron aún más. Puesto que los informes médicos fueron evaluados, ya no sólo por el Capitán de Puerto sino también por el señor Ampuero, prefecto de la provincia del Callao, siendo él quien tomó la decisión de qué hacer con las tripulaciones que llegaban al puerto.

Ayer ha fondeado en este puerto la fragata italiana "Unncowah" procedente de Macao en 96 días. Trae á su bordo 491 colonos asiáticos de 498 con que salió del puerto de su destino, por haber muerto 7 durante la navegación. Practicada la visita de sanidad, solo se ha encontrado 4 enfermos por el abuso del opio, según el certificado del médico titular, y el resto de pasajeros y tripulación se halla en el mejor estado de salud. En tal virtud, se ha dejado en libre comunicación á dicha fragata, y he dispuesto que no sea desembarcado ningún colono hasta que usted resuelva lo conveniente, con cuyo objeto tengo el honor de poner lo ocurrido en su conocimiento de u.s. para los fines que crea convenientes ${ }^{40}$

De la anterior cita se desprende que a pesar de que la embarcación italiana procedente de Macao con 491 chinos no se encontró personas con indicios de fiebre amarilla a esta se le prohibió desembarcar a los pasajeros debido a que eran chinos y ello era suficiente razón para ser sospechosos de portar el mal, pues que sus malos hábitos como fumar opio, ser pocos higiénicos, sumado a las condiciones deplorables en las que viajaban y además provenir de una zona tropical de donde era oriunda la enfermedad, los hacían más que sospechosos de portal este mal.

El prejuicio hacia los chinos que llegaban al Callao durante la epidemia de 1868 sólo se evidenció al momento de impedirle su desembarco también este se dio al momento de estar ya autorizado para desembarcar

Anoche á las siete y media, he recibido la nota de u. s. que ha dispuesto esa prefectura para evitar el desarrollo epidémico á borde de los buques que estan fondeando en la bahia tomando la misma medida, esto es la de mandar á esos infelices á la Ysla de San Lorenzo por unos dias para que pueda refrescarse, pero como no tenia la autorización suficiente para ello, solo habia hecho que el Sr. Dr. Aranda pasara una visita á todos los cinco buques y que me diera una razón minuciosa del número de Chinos que hay en cada uno como

38 El Comercio, publicación del 23 de marzo de 1868.

39 Archivo Histórico de Marina, sección Prefectura del Callao, caja 25, sobre 3, folio 18. Informe del Capitán de Puerto al Prefecto del Callao del 24 de marzo de 1868.

40 Archivo Histórico de Marina de Guerra del Perú, sección Prefectura del Callao 1868, caja 3, sobre 25, folio 3. Informe del Capitán de Puerto al Prefecto del Callao del 30 de enero de 1868. 
igualmente el de los enfermos, para que esto me sirviera de base para el parte diario que cada Capitán de los navios me ha estado pasando, en el que me han puesto el número de los que escisnte, de los que se venden y la persona que compra, como tambien los que los que se enferman y mueren, tomando la precausion de mandar á un cabo de matricula hasta la Ysla con el objeto de que presencie el que lo sepulten en una profundidad que no quede el cadáver sobre la superficie.

Ademas de esta medida he mandado entre dias á un ayudante á visitar esos buques, para tener seguridad del aseo de estos y del personal de ellos.

Hoy mismo he ordenado, que los Capitanes de los cinco buques, ya sea embarcaciones menores ó con sus mismos buques pasen los colonos á la Ysla, dando asi cumplimiento á lo que u. s. ha dispuesto y dejando asi mismo contentada su citada ${ }^{41}$.

Como se nota el Capitán de Puerto Manuel Palacios envía al médico encargado don Marcelino a Aranda a pasar inspección médica a los 5 buques que se encontraban descargando en el muelle del Callao es decir que ya habían pasado su respectiva inspección al momento de arribar al puerto, esto no tendría nada de extraño en coyuntura crítica como la del 1868 en la cual se buscaba evitar la propagación de la fiebre, no obstante, notamos un acto prejuicioso en el sentido que solicitar al referido médico se haga una lista del total de chinos y aparte una de los enfermos, lo más lógico era solicitar una lista del total de enfermos para mandarlos a hacer cuarentena a la isla San Lorenzo al margen de la nacionalidad, sin embargo se pide una lista de chinos puesto que la intención era enviar a aquello "infelices" chinos hacer cuarentena a la Isla para que se refresquen un rato a pesar de no encontrarse enfermos.

Como se ha visto anteriormente de acuerdo a lo planteado en la tesis del doctor Isaias Morales Pacheco la aglomeración de individuos en habitaciones, la humedad, la miseria, los desórdenes y excesos de todo género producían las condiciones necesarias para que los miasmas tomaran control del espacio y se desarrollaran, bajo esta idea los arquetipos fundado hacia los chinos como personas poca higiénicas y viciosas alimentaban la creencia de que ellos eran portadores del mal y su sola presencia causaba estragos de allí los constante prejuicios hacia ellos.

En todo tiempo son un peligro las repugnantes tiendas de asiáticos, pero nunca más que ahora, y sobre todo cuando se saben que aquellos son propensos a padecer y contagiarse [sic] de enfermedades como esta, por el poco aseo y pésimo alimento que acostumbran. Siempre hemos reclamado para que se proscriba a los asiáticos de las calles Paz - Soldán y demás donde tienen su residencia, pero desgraciadamente siempre han sido desatendidas nuestras indicaciones al respecto [...] Esto debe particularmente debe influir en el ánimo de la autoridad municipal para que en la mayor brevedad haga trasladar a los asiáticos a distintos lugares, pues la acumulación en la que ahora se encuentran dando lugar a mil contingencias y dañando la salubridad pública, dará por resultado, necesariamente, el desarrollo violento y rápido de la fiebre amarilla entre los asiáticos que infestarán por consiguiente todo el vecindario ${ }^{42}$.

El prejuicio realizado hacia los chinos no sólo se restringió en la zona del puerto, sino también se dio en otras esferas públicas como por ejemplo los hospitales. Cabe mencionar además que el control ejercido en el puerto no se dio de manera exclusiva hacia ellos (pero si con un gran énfasis) tal como lo podemos evidenciar en el siguiente caso, no obstante, debe precisarse que fue el único que logró identificarse:

El Vapor ingles Perú que ha fondeado el día de hoy en este puerto procedente de Panamá y Paita, trae su patente limpia y según el certificado del médico, tanto los pasajeros como

41 Archivo Histórico de Marina de Guerra del Perú, sección Prefectura del Callao 1868, caja 3, sobre 25, folio 16. Informe del Capitán del Puerto al Prefecto del Callao del 22 de marzo de 1868.

42 Diario: El comercio, publicación del 23 de marzo de 1868. 
los individuos de su tripulación, se hallan en perfecto estado de salud, en cuya virtud ha quedado en libre comunicación.

Entre los pasajeros que ha conducido á este puerto se encuentran los españoles señores Pedro Marquez, Balentin García y Manuel Gomes á quienes he notificado que no salten á tierra hasta que u. s. tenga á bien ordenarlo. Lo que tengo el honor de poner en conocimiento de u. s. para los fines que crea conveniente ${ }^{43}$.

\section{Conclusiones}

La epidemia de fiebre amarilla que asoló a Lima y al Puerto del Callao en el año de 1868, nos permite ver que la discriminación y prejuicios que se construyen entorno al otro (para este caso al migrante chino) perduran hasta la actualidad, puesto que se suele señalar a aquellas personas que no comparten nuestras mismas costumbres, hábitos (en términos actuales encontramos el caso de los inmigrantes venezolanos) como los responsables de aquellos hechos que aquejan a nuestra sociedad (delincuencia, carencia de trabajo) sin darnos cuenta, que el origen de dichos problemas no son producto de nuestra diversidad cultural, sino más bien de las carencias del conocimiento científico (para el caso de la fiebre amarilla, se creía que ella producto de los miasmas que habían sido introducidas por los migrantes chinos, cuando en realidad esta se producía por picadura del mosquito Aedes aegypti) o en el peor de los casos de la organización y regulación del Estado (para el caso de los inmigrantes venezolanos, los problemas de inseguridad ciudadana y carencia de trabajo responde a problemas estructurales como el de la educación, modelo económico, organización territorial).

\section{Bibliografía}

\section{Fuentes Primarias}

Archivo histórico de la Facultad de Medicina de la UNMSM, CASSET, C (1868). De la fiebre Amarilla en el Perú. Lima: Tipografía y encuadernación de A. Alfaro y Ca.

Archivo histórico de la Facultad de Medicina de la UNMSM: MORALES PACHECO, Isaias (1891). Fiebre Amarilla en el Callao en los años 1888 y 1889. Tesis para obtener el grado de Bachiller en la Facultad de Medicina de la UNMSM.

Archivo Histórico de la Marina de Guerra del Perú, sección Prefectura, 1868.

Bonilla, Heraclio (1976). "Informe sobre el movimiento comercial del Callao de 1867 a 1870 y parte de 1871 por H. Hutchinson". En Gran Bretaña y el Perú 1826 - 1919. Informes de los cónsules británicos. Volumen III. Lima: IEP - Fondo del libro del Banco Industrial del Perú.

Cisneros, Carlos; García, Rómulo (1898). Guía del viajero. Callao, Lima y sus alrededores. El Comercio, 1868.

Flores, Toribio (1862). Compilación de las leyes expedidas desde el año 1821, en lo relativo al servicio de las capitanías de los puertos y de las matrículas, ó sea, guía del comerciante y del banquero, en cuanto á las leyes de la Marina mercante. Callao: Imprenta de M. Gómez y J. Aparicio.

Fuentes secundarias

BUENAÑO, Javier (1999). “Capitán de Navío Aurelio García y García”. En Héroes y marinos notables. Lima: Ministerio de Marina - Dirección General de Intereses Marítimos, p. 139 $-151$.

CASALINO, Carlota (2001). La muerte en Lima en el siglo XIX: una aproximación demográfica, política, social y cultural. Tesis para obtener el grado de Magister en Historia. Lima: PUCP. 
CONTRERAS, Carlos; CUETO, Marcos (2007). "República del guano". En Historia del Perú contemporáneo, cuarta edición. Lima: IEP - PUCP - Centro de Investigación de la Universidad del Pacífico, p. 113 - 160.

CUETO, Marcos (1989). “Tradición médica, bacteriología e intervención extranjera en el Perú: 1884 - 1930". En Excelencia científica en la periferia. Lima: Grupo de análisis para el desarrollo - Consejo Nacional de Ciencia y Tecnología, p. 119 - 159.

CUETO, Marcos (2000). "Sanidad desde arriba: La fiebre amarilla, la costa norte y la fundación Rockefeller". En El regreso de las epidemias. Salud y sociedad en el Perú del siglo XX. Lima: IEP, p. $59-86$.

GOOTENBERG, Paul (1998). "El descontento del Guano". En Imaginar el desarrollo. Las ideas económicas en el Perú poscolonial. Lima: IEP - BCRP, p. 65- 91.

GUMERÁ, Agustín (2002). “Puertos y Ciudades portuarias (Ss. XVI - XVIII): una aproximación metodológica”. En Litoral en perspectiva histórica (Séc XVI a XVIII), p. 287- 305.

HUDTWALCKER MORÁN, José. "Las islas del Callao en los albores del siglo XX: apuntes para su historia". Revista de Marina. Número 3, año 2008, p. 3- 18.

LOSSIO, Jorge (2003). Acequias y gallinazos. Salud ambiental en Lima del siglo XIX. Lima: IEP.

MÜCKE, Ulrich (2010). "Burguesía limeña”. En Política y burguesía en el Perú. El partido civil antes de la guerra con Chile. IFEA - IEP, 2010, p. 37 - 83.

RAMÓN JOFFRÉ, Gabriel (2004). El guión de la cirugía urbana: Lima 1850 - 1940. En Ensayos en Ciencias Sociales (3) Recuperado de http://sisbib.unmsm.edu.pe/bibvirtualdata/libros/ CSociales/ensayos_ciencias/v1n1/a02.pdf.

SHANE, Hunt (2011). "Guano y crecimiento en el Perú del siglo XIX". En La formación de la economía peruana. Distribución y crecimiento en la historia del Perú y América Latina. Lima: IEP, p. $71-163$.

RODRÍGUEZ PASTOR, Humberto (2012). "El inicio de la trata amarilla al Perú y sus actores". En La inmigración china al Perú. Arqueología. Historia y Sociedad. Lima: Universidad Ricardo Palma - Instituto Confucio - Editorial Universitaria, p.65 - 110.

ROTTENBACHER, Jan (2013). Emociones colectivas, autoritarismo y prejuicio durante una crisis sanitaria: la sociedad limeña frente a la epidemia de la fiebre amarilla de 1868 (tesis de posgrado). PUCP, Lima, p. 89.

ZÁRATE, Eduardo (2014). La mayor epidemia del siglo XIX. Lima, 1868 fiebre amarilla. Lima: Eduardo Zárate Cárdenas. 


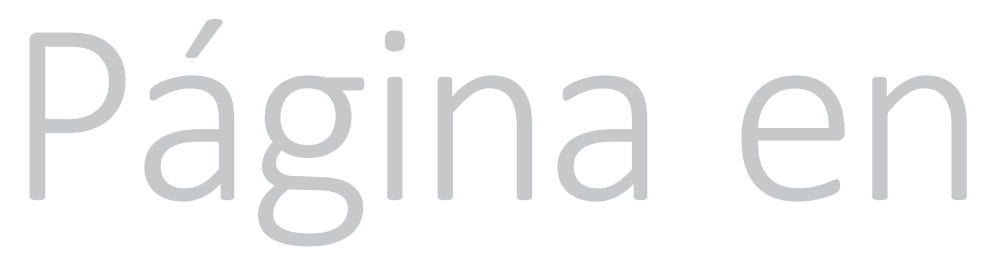

blanco 